\title{
UMA ASSINATURA DE EÇA: A RETÓRICA DA VISUALIDADE EM A RELÍQUIA
}

Pedro Schachtt Pereira

Brown University

\author{
Sarah, Sarah, par qui le \\ monde commence? \\ - Par la parole? \\ - Par le regard?
}

Edmond Jabès, Le Livre des Questions

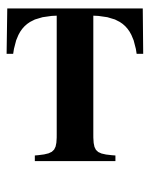

alvez a principal fonte da inesgotável perplexidade a que nos convida o realismo, enquanto escrita do real, tenha a o seu paradoxo essencial: quanto mais tomamos como certo o real por ele mostrado, menos o entendemos. ${ }^{1}$ A ilusão realista, para funcionar na narrativa, tem de construir-se em permanente véu das suas premissas tropológicas. Já aqui, no indecidível lugar do entrecruzamento desta cena de velamento/desvelamento, a perplexidade pode começar: no campo visual da ficção realista, cujo sonho é o de uma mediação sem resto da realidade, cabe toda a realidade menos a realidade do véu, a do ocultamento originário da própria escrita. Sem dúvida há algo de alucinatório nesta cena. Mas esgotar-se-á nela toda a história do realismo? Será o realismo a

${ }^{1}$ Menos entendemos o real, mas sobretudo menos entendemos o realismo. Este é o argumento principal que Nancy Armstrong desenvolve num estudo, ainda inédito, sobre a importância da fotografia no desenvolvimento da ficção realista oitocentista inglesa. Cf. ARMSTRONG; "Fiction in the Age of Photography", p.1. Da mesma premissa parte um interessante estudo de Lilian R. Furst, All is True - The Claims and Strategies of Realist Fiction. 
apologia de uma 'visão monocular', tal como um certo 'ponto de vista' do modernismo nos fez acreditar? Ou, para adensar ainda mais o panorama, será que um certo discurso crítico que se impôs sobre o realismo não partilha da mesma alucinação, da mesma miopia, enfim, de uma certa cegueira? Ao longo deste estudo, em que aquilo que estará em questão é essencialmente o ponto de vista, e a forma como ele se torna um tema na experiência novelística de Eça de Queiroz, procurarei decifrar aquilo a que chamo a retórica da visualidade na escrita de A Relíquia: a sua emergência no interior de uma cena de herança, em que aquilo que se herda é antes de mais uma determinada usura da visão, sempre já sobredeterminada por uma dissipação cega, por um determinado excesso de visão que nenhum panorama, nenhum campo visual pode fechar: em suma, a herança como cena mais ampla do que o quadro que a (circun)escreve. Por outro lado, a necessidade (no sentido filosófico do termo) com que tal retórica se impõe quer ao escritor quer ao leitor perpassa de igual forma o processo de decifração que aqui se ensaia. Nesse sentido, tentarei mostrar como a recepção crítica da obra de Eça, ao não levar em conta a importância que a visualidade tem de uma maneira geral na organização do discurso estético oitocentista, tem passado ao lado do motivo $^{2}$ que entretece a própria

${ }^{2}$ A visualidade é, enquanto marca que entretece o discurso, um motivo e não um tema. Esta distinção, que estabeleço aqui na pegada de Jacques Derrida, parece-me fundamental na medida em que o motivo é aquilo que permite que algo como um tema, uma tese, uma paragem, existam como tal. O motivo implica movimento, tessitura, repetição:

O motivo, ao contrário do tema, ou como excesso do tema, reconduznos aos lugares onde, porque os critérios de decidibilidade já não estão assegurados, uma decisão pode então comprometer-nos. E o acontecimento pode então ter lugar. (DERRIDA, 1986, p. 20).

O motivo dá-se a ler em citação, nesse movimento se inscreve e nele inscreve quem escreve. Citação deve entender-se, como Derrida sublinha, no seu sentido latino, a um tempo ético e jurídico: incitação, solicitação. (DERRIDA, 1986, p. 20). 
obra, isto é, daquilo mesmo que na obra permite que existam os temas de que a crítica se ocupa. Devo dizer que pouco de inédito há nesta minha iniciativa de leitura: ela reflecte apenas o movimento em curso há já vários anos sobretudo no âmbito dos estudos franceses e anglo-americanos, um movimento de re-avaliação do realismo enquanto discurso mas também do próprio discurso crítico sobre o realismo. A bibliografia neste domínio e nesses quadrantes geográfico-culturais não pára de crescer e ultrapassa já em muito aquilo que um trabalho destas dimensões pode e deve citar. Por outro lado, a questão da retórica da visualidade assume em Eça de Queiroz nuances demasiado complexas que aqui conhecerão uma formulação não mais do que introdutória. Limitar-me-ei a assinalar no texto de A Relíquia os três momentos em que penso encontrar manifestações suficientemente claras de uma tal retórica, e desses três, apenas um merecerá uma análise tanto quanto possível detalhada.

Porquê retórica da visualidade? Mesmo que não haja dificuldade em admitir o papel privilegiado que a visão ocupa na escrita realista (admitindo sem discussão a existência de uma tal escrita, o que não se poderá ser feito sem o assumir de um certo risco), qual a necessidade de entender esse papel e esse privilégio como retórica? Quando em La Peau de chagrin uma personagem pergunta a certa altura: "Voir n'est-ce pas savoir?" esta pergunta é já aquilo a que se convencionou chamar uma pergunta retórica, isto é, uma falsa pergunta, nada mais do que uma ficção de ignorância, que apenas vem confirmar uma certeza previamente admitida como tal. Esta pergunta, na sua transferência de Balzac para Eça de Queiroz, irá de resto perder o seu carácter ardilosamente interrogativo, mas irá também adquirir uma outra marca de complexidade, ao ser inscrita num registo de ambivalência crítica em relação aquilo a que podemos chamar o universo da crença: ver não será apenas conhecer, mas sobretudo um conhecer que se sobrepõe ao monopólio cultural de uma crença: a do catolicismo do padre Amaro, a do romantismo do conselheiro Acácio, a do "patrioteirismo" de Pinheiro Chagas. A certeza epistemológica do realismo, segundo a 
qual ver é conhecer e que se expressa numa escrita que nada pretende ser senão uma expressão imediata da visão imediata da realidade, é uma visão que se deseja sobrepôr a uma visão: um olho hipertrofiado que se enxerta num olho míope. Ver sobre crer. Como veremos, esta enxertia não se deixa cristalizar numa oposição dialéctica, ela dá-se antes a ler numa ambivalência indecidível, sendo esta indecidibilidade e a forma como se manifesta na linguagem da visualidade, na visualidade como linguagem, a porta de entrada, desde sempre aberta, desde sempre fechada, da retórica. ${ }^{3}$ Será despropositado assinalar que esta ambivalência ao nível da definição do campo visual se manifesta em Eça de Queiroz logo no início da sua carreira, quando profere no Casino Lisbonense a conferência: "A literatura nova. O realismo como expressão da arte"? Numa 'performance' toda ela delineada segundo paradigmas visuais (sabemos que Eça se apresentou para esta conferência envergando uma indumentária que A. José Saraiva define como "espalhafatosa" sendo o intuito mais directo o de chocar, seduzir, "dar nas vistas"). Idênticos intuitos animam o próprio discurso, um tudo nada

${ }^{3}$ Mais do que um mero jogo de palavras, pretende-se aqui marcar a indecidibilidade que, remarcando sempre a dimensão linguageira do discurso, o faz no momento mesmo das afirmações mais categóricas desse discurso, nos momentos em que tal dimensão é pelo discurso velada. Teoria e cegueira* foi como muito perspicazmente Paul de Man nomeou esta ambivalência: a cegueira da teoria escreve-se com a mesma mão com que se escreve a sua certeza; o momento de formulação categórica de uma teoria é o momento em que aquele que escreve mais cego está em relação à escrita das implicações teóricas do seu posicionamento crítico, ou dessas implicações teóricas como escrita. Cf. Blindness and Insight, Essays in the Rhetoric of Contemporary Criticism. *Teoria e cegueira é a minha tradução provisória para Blindness and Insight. Os equivalentes portugueses para insight não acompanham o dinamismo que a palavra tem na língua inglesa; tanto "introspecção" como "visão interior" ou mesmo "intuição" são termos com uma carga semântica demasiado determinada na nossa cultura.

${ }^{4}$ Cf. SARAIVA, 1995, p.45-46. 
sofístico, um discurso forte, em que a palavra é tanto logos como é pharmakon, como entender a apologia de um certo invisível que em igual medida se produz neste texto? Citemo-lo amplamente:

[O realismo] É a negação da arte pela arte; é a proscrição do convencional, do enfático e do piegas. É a abolição da retórica considerada como arte de promover a comoção usando da inchação do período, da epilepsia da palavra, da congestão dos tropos. É a análise com o fito na verdade absoluta. - Por outro lado, o Realismo é uma reacção contra o Romantismo: o Romantismo: o Romantismo era a apoteose do sentimento; - O Realismo é a anatomia do carácter. É a crítica do homem. É a arte que nos pinta a nossos próprios olhos - para condenar o que houver de mau na nossa sociedade. ${ }^{5}$

Como é suposto lermos este parágrafo, quando sabemos que os princípios desta "arte que nos pinta a nossos próprios olhos", os quais devem passar a reger toda a prática realista da escrita de Eça, foram aprendidos na leitura de um quadro de Courbet, o qual Eça explica apaixonadamente sem nunca o ter visto? ${ }^{6}$ Será o carácter absoluto da verdade, que é fito da análise do escritor realista, a herança de uma certa contemplação do invisível? A partir daqui, entre o ver e o crer, só na assunção de um risco desmedido é possível a escolha.

Em A Reliquia, a ambivalência entre ver e crer mantém-se, mas radicaliza-se. Ela apresenta-se primeiro como uma dicotomia, como uma alternativa que o narrador, ao compôr as suas memórias, pretende dar a pensar aos seus leitores. Dar a pensar a alternativa entre Eros e Cristo, as duas figuras tutelares do seu percurso biográfico e da narração que dele pretende dar conta. A peripécia da troca dos embrulhos, que se deixa adivinhar no título, de alguma forma sumariza esta visão alternativa, mas anuncia também, pareceme, a dissolução desta alternativa numa ambivalência indecidível. Aquilo que se segue é uma tentativa de traçar o mapa ou o itinerário

${ }^{5}$ LOPES, 1985, p. 926.

${ }^{6}$ Cf. SARAIVA, 1995, p. 46. 
da manifestação dessa indecidibilidade, tal como uma releitura de A Relíquia me sugeriu fazer. Mas nesta (re)leitura, a indecidibilidade é sempre já constitutiva do traço, do itinerário e do mapa.

Os três momentos, acima assinalados, de uma manifestação nítida da visualidade como retórica em A Relíquia, são os seguintes:

O voyeurismo. O olho atrás da fechadura, como antecipação nunca actualizada de uma visão total, em cuja promessa participa o leitor. Este motivo deixa-se ler no episódio narrado nas páginas 99-100, em que Teodorico é surpreendido pelo lorde inglês a espreitar pela fechadura do quarto da filha que se banha. Não seria difícil ver aqui uma certa melancolia narcísica, em jogo permanente com uma ferida narcísica, necessariamente relacionada com a frustração dessa visão total. ${ }^{7}$ Num interessante estudo, "Censoring the realist gaze", Jann Matlock relaciona o voyeurismo, tal como ele surge na narrativa oitocentista francesa, com uma representação do olhar auto-censurado. O realismo seria a história da fantasia de um olhar e das ansiedades a que tal fantasia dava lugar. Assim sendo, o realismo não pode ser a apologia de um olhar sem mediação, como vulgarmente se crê, pois que um tal olhar investe-se sempre já no espaço da censura. ${ }^{8}$

A visão onírica. Ela anuncia-se logo no início, na viagem que leva Teodorico órfão desde a casa paterna até Lisboa, onde se encontrará face a face com o seu destino, tal como este foi delineado pela tia Patrocínio (o mesmo é dizer: uma certa tradição ou herança católica, piegas, inquisitorial e beata). A meio dessa viagem o pequeno Teodorico sonha que a certa altura, ao seu lado "ia andando um homem nú, com duas chagas nos pés, e duas chagas nas mãos, que era Jesus Nosso Senhor". ${ }^{9}$ Esta figura, como se sabe,

\footnotetext{
${ }^{7}$ Este motivo, na sua relação com o que designamos por "autobiografia", é magistralmente lido em DERRIDA, 1990.

${ }^{8}$ MATLOCK, 1995, p. 57-58.

${ }^{9}$ QUEIROZ, s.d., p. 13-14.
} 
será revisitada por Teodorico noutro sonho, passado em terras da Palestina, durante o qual assiste à paixão e morte de Cristo na sua versão renaniana. Sabe-se também o que de exemplar tem este sonho na economia de uma narrativa que pretende mostrar as consequências catastróficas, aos níveis pessoal, cultural e social, daquilo que o narrador reputa ser uma falsa interpretação do episódio evangélico. O que chama a atenção neste episódio para uma leitura que se preocupa com a retórica da visualidade, é não tanto o jogo das interpretações e das ideologias que lhe são subjacentes, até porque tudo isso tem sido desde sempre discutido pela crítica queirosiana, como sobretudo as convenções retóricas em que tal episódio se enquadra, e a forma como se transfere para o leitor a responsabilidade de decidir quais imagens e qual discurso são reais, e quais são sonho. De quais imagens é o narrador contemporâneo, as que se lhe mostram no sonho exemplar, ou as que se lhe deparam na sua deambulação picaresca por uma Jerusalém decadente, feia e suja. Ainda aqui estamos perante um problema de ponto de vista.

A visão alegórica. Este é o momento no qual me detenho com mais vagar, porque é o que permite ler com mais proveito os dois momentos anteriores, e é o momento no qual me reencontro com a necessidade da minha releitura. A visão alegórica constitui em $A$ Relíquia um elemento reflexivo numa composição textual que se pretende como mimética. Nela, é o acto mesmo de ver que se representa, não apenas duplicando a visão do narrador, mas sobretudo mostrando a visão como problema. Em todas as cenas alegóricas, o que se põe em jogo é desde logo uma alegoria da visão, uma especulação sobre a possibilidade mesma da visão a partir de um ponto de vista sempre ameaçado por uma ruína originária: um ponto de vista que se dá na perda, o ponto de vista da reapropriação impossível de si-mesmo, na linguagem como fora dela, no discurso que pretende apagar a linguagem e que nela constroi tal pretensão, no discurso onde a linguagem regressa celebrando a ruína da narrativa autobiográfica exemplar, ou a narrativa exemplar 
como ruína. ${ }^{10}$ Ainda que não seja o meu fito a análise do carácter autobiográfico (complicado pela sua inscrição do ficcional) desta narrativa, parece-me que é nestas linhas que ela deve ser lida. Esta cena alegórica, que se dá a pensar na sua exemplaridade abissal, encontro-a no discurso que a consciência de Teodorico para si mesma profere, transfigurada no Cristo crucificado que orna a parede do quarto de pensão onde aquele se encontra, no momento em que lhe chega o resto da herança da tia Patrocínio. Uma cena de herança, que se mostra num panorama epifânico, o mesmo é dizer, alucinatório. No mesmo panorama temos que ler a cena de conversão despoletada pela chegada da herança, ou do que dela resta. Dificilmente o acaso explicará que tal resto se materialize num instrumento de óptica, programado para permitir a visão próxima do que é longínquo: "um velho óculo de alcance, relíquia do comendador G. Godinho". ${ }^{11}$ A vida de Teodorico Raposo, toda ela programada no rasto de uma herança, é premiada pelo que dessa herança não se fazia esperar: a chegada da verdade longínqua, a que prescreve o que deve ser visto e como devia ter sido vista essa vida. Esta é a aventura que faltava para que todas as outras revelassem o seu carácter exemplar, é a última aventura na trajectória de um pícaro que acaba por se converter, não pela viagem que efectuou, mas por aquilo que lhe dá acesso à compreensão dessa viagem. Antes de avançar mais, devemos determo-nos no texto, no momento do texto em que se regista esta aparição:

Do testamento da virtuosa senhora, consta que deixa a seu sobrinho Teodorico o óculo que se acha pendurado na sala de jantar... [...]

E, de resto, dispersara no seu testamento as riquezas de G. Godinho, do modo mais incoerente e mais perverso.

${ }^{10}$ Uma vez mais pretendo aqui seguir o rasto de uma leitura que Jacques Derrida leva a cabo em Mémoires D’aveugle - L'autoportrait et autres ruines, p. 9-10.

${ }^{11}$ QUEIROZ, s.d., p. 33. 
[...] A Vicência tivera as roupas de cama. Eu - o óculo.

- Para ver o resto de longe! - considerou filosòficamente o Justino, dando estalidos nos dedos. ${ }^{12}$

[...]

Era o óculo. Mandava-mo o Justino, com estas palavras amigas: "Aí vai a modesta herança!"

Acendi uma vela. Com áspera amargura tomei o óculo, abri a vidraça - e olhei por ele, como da borda de uma nau que vai perdida nas águas. Sim, muito sagazmente o afirmara Justino, a asquerosa Patrocínio deixava-me o óculo com rancoroso sarcasmo - para eu ver através dele o resto da herança!

[...]

Ali estavam, esse capacete e esse óculo, emblemas das minhas duas existências - a de esplendor e a de penúria!

[...]

E agora, com o óculo, eu era o pelintríssimo Raposo de botas cambadas, sentindo em roda, negros e prontos a ferirem-me, todos os cardos da vida... ${ }^{13}$

Uma vela acende-se como que em memória de uma certa nau catrineta... O óculo não apenas desencadeia a fúria e agudiza a angústia de Teodorico, ele desperta também a sagacidade filosófica de Justino. O óculo traz para a cena de herança em que Teodorico se revê como pícaro uma reserva de filosofia. E a re-visão filosófica do seu percurso é o que permite a Teodorico entender o que viu durante as suas viagens - a que faz em criança, da casa paterna para Lisboa, e a que sonha durante a sua permanência na Palestina, na qual assiste ao episódio evangélico da paixão, episódio cujo significado só o discurso da consciência transfigurada em Cristo lhe pode desvendar -; o óculo é o que permite a Teodorico aceder da cegueira em que conduziu a sua vida, a um tempo beata e devassa, à visão em que essa vida se redime, através do encontro com a sua verdade escondida. Não será excessivo lembrar que é este encontro

12 QUEIROZ, s.d., p.262.

${ }^{13}$ QUEIROZ, s.d., p.263. 
que possibilita a própria narrativa: só a re-avaliação da sua vida transforma Teodorico num escritor. Uma coisa é haver uma viagem para contar. Outra, é saber como e porquê contar essa viagem. $A$ Relíquia conta a história da ascensão a esse saber. A história de como o saber, que se conquista vendo, é sempre de uma ordem superior à do crer. Esta superioridade é terrena, e já não celeste, como a miopia beata poderia levar a crer, e neste aspecto, o óculo conta também uma história de hierarquias, de genealogia e de parricídio:

Eu pergunto-te agora se não te lembras da minha voz... Eu não sou Jesus de Nazaré, nem outro Deus criado pelos homens... Sou anterior aos deuses transitórios: eles dentro em mim nascem; dentro em mim se transformam; dentro em mim se dissolvem: e eternamente permaneço em torno deles e superior a eles, concebendo-os e desfazendo-os, no perpétuo esforço de realizar fora de mim o Deus absoluto que em mim sinto. Chamo-me a consciência; sou neste instante a tua própria consciência reflectida fora de ti, no ar e na luz, e tomando ante teus olhos a forma familiar, sob a qual, tu, mal educado e pouco filosófico ${ }^{14}$ estás habituado a compreender-me... Mas basta que te ergas e me fites, para que esta imagem resplandecente de todo se desvaneça. ${ }^{15}$

Este discurso contidamente filosófico tem o poder de se autonomear, de dar a si mesmo o seu nome: é um discurso sem Pai, que se anuncia como pai de todos os discursos. Na afirmação deste discurso repercute uma outra voz: não seria esta afirmação aquilo a que o jovem Eça obrigava a sua geração a perseguir sob o nome de Realismo, na 4⿳亠丷a Conferência do Casino, quando dizia: "O Realismo [...] é a crítica do homem. É a arte que nos pinta a nossos próprios olhos..."? Esta é a herança, e esta é também a autêntica relíquia de A Reliquia. Teodorico herda, com o óculo, o discurso que Eça de Queiroz não consegue impor ao seu tempo, e do qual Eça começa a ver como que em espelho a verdadeira face: antes de ser o discurso através do qual se pode narrar a realidade, e a realidade

\footnotetext{
${ }^{14}$ Os grifos são nossos.

${ }^{15}$ QUEIROZ, s.d., p. 267.
} 
portuguesa do seu tempo acima de tudo (e através dessa narração redimir essa realidade), o discurso do óculo é o discurso no qual se conta a sua vida, a sua vida como sonho da eficácia e clarividência de um discurso, a sua vida como escrita. O óculo é um espelho que se interpõe entre Teodorico e Eça de Queiroz, e que reflecte a imagem de um homem, de monóculo, a escrever. O relato autobiográfico de Teodorico, onde Eça de Queiroz se implica ironicamente, é antes de mais a autobiografia do relato, a história de como Eça se encontra com a escrita. A escrita das memórias é sempre já uma escrita testamentária, em memória da escrita. A crítica queirosiana sempre viu em A Relíquia um ponto de viragem na trajectória ficcional de Eça de Queiroz. Para tal baseava-se essencialmente numa interpretação ingénua da epígrafe do livro: "Sobre a nudez forte da verdade - o manto diáfano da fantasia". $A$ Relíquia, O Mandarim, A cidade e as serras e A Correspondência de Fradique Mendes eram caracterizadas como obras de uma hipotética "3믈 fase" em que se dava um passo na direcção da fantasia, ${ }^{16}$ abandonando-se o programa realista da juventude. Por outro lado, seriam obras em que Eça assumia a responsabilidade de narrar na primeira pessoa, com todas as consequências que isso acarreta ao nível da narrativa. O que essa crítica sempre teve dificuldade em explicar, talvez porque não sentisse isso como uma dificuldade, é o estatuto de "manto diáfano" dessa fantasia. Como funciona, de onde surge esse manto? E o que cobre esse manto? - A nudez crua da verdade. Mas o que há na verdade que exija a realidade do manto? Como se impõe este manto, e que há de insuportável ou invisível naquilo que ele cobre para que a sua função seja invocada? Tantas perguntas a que aqui pouco mais será possível fazer para responder senão lançar uma suspeita nas respostas um tanto precipitadas de uma certa crítica. É que, ao caracterizar A Relíquia como uma viragem para a fantasia, a crítica permanece enredada na dicotomia que em $A$ Relíquia se desconstrói: a dicotomia entre

${ }^{16}$ LOPES, 1985, p. 938. 
verdade e fantasia, entre realidade e ilusão, entre ver e crer. E é a permanência nessa dicotomia que não permite a essas leituras aperceberem-se que a fantasia a que a epígrafe de $A$ Relíquia se refere é a fantasia ou a ficção constitutiva do próprio discurso crítico sobre o real. "Fantasia" já existia em As Farpas, O Primo Bazílio e em Os Maias. O que acontece em A Relíquia e nas obras subsequentes é que Eça descobre essa fantasia como fantasia da escrita: Eça descobre-se como escritor no próprio momento em que escreve, e mais descobre que, quando escreve sobre o real e a fantasia, é sempre já e antes de mais sobre o facto de sobre isso escrever que ele escreve. Exemplo das dificuldades com que se debate a crítica cega em relação aos seus próprios pressupostos é o fascinante texto de A. José Saraiva, que deve ser citado amplamente:

[...] mesmo na fase "realista" da obra de Eça há vários romances que programaticamente nada têm de realistas, como OMandarim, A Cidade $e$ as Serras, A Ilustre Casa de Ramires, e até onde falta qualquer propósito de coerência e de verosimilhança, como A Reliquia. ${ }^{17}$ [...]

Ainda não está aqui bem desabrochada a ideia da arte como "fingimento" segundo a fórmula de Pessoa, mas há a da arte como "manto diáfano"; recobrindo o quê? O manto diáfano é o manto sensorial, o manto da "sensualidade" de que Eça falava a Martins, as aparências sedutoras com que nos atraem as coisas, a maia dos Budistas. Esse manto é como as visões de Santo Onofre, a mulher nua que abre os braços na gruta do solitário do deserto. Ele corre para o corpo que se lhe oferece e que de repente se dissipa e se lhe furta, porque tudo era aparência, tudo era sensualidade. O "manto diáfano da fantasia" veste um oco. No extraordinário conto José Matias, o narrador, o biógrafo do protagonista, apresenta-se, na conclusão, como um "metafísico" que "comentou Espinosa e Malebranche, reabilitou Fichte e provou suficientemente a ilusão da sensção. Essa ilusão é o problema essencial da estética de Eça de Queiroz. ${ }^{18}$

${ }^{17}$ QUEIROZ, s.d., p. 149-150.

${ }^{18}$ QUEIROZ, s.d., p. 153-154. 
O que fascina neste excerto é não tanto as pistas interessantes que nele se avançam em relação à possível interpretação da epígrafe de A Relíquia, como sobretudo a forma como nele vemos um crítico a prestar contas à sua herança lukácsiana, e a experimentar um certo desconforto, uma certa estreiteza dentro dela. A influência de Lukács parece-me ainda mais óbvia no estudo As Ideias de Eça de Queiroz, no qual A. José Saraiva defende o ponto de vista segundo o qual as últimas obras de Eça apontam para uma desistência em relação à intervenção política e à assunção de um discurso da desilusão, da comodidade e do pitoresco. Já Lukács tinha interpretado como decadência do realismo toda a produção novelística subsequente a 1848, na qual ele regista uma infusão do "detalhe ornamental", de um "panorama imóvel", do "pictorialismo", de uma "atmosfera pitoresca" e uma "autenticidade fotográfica". ${ }^{19}$ Algumas leituras mais recentes, dando conta desta escrita abissal, têm sugerido a antecipação por Eça de Queiroz de um certo "pós-modernismo". ${ }^{20}$ Não vou discutir aqui a pertinência desse termo para a leitura dos fenómenos literários em geral, já que essa seria uma discussão que, apesar de fascinante, em muito ultrapassa os limites desta reflexão. Mas devo apontar aquilo que penso ser a impertinência de uma tal categoria para a leitura do passo de Eça de Queiroz que aqui estamos a ler mais de perto. Se é verdade que esta indecidibilidade entre visão e crença, entre verdade e fantasia, se promete como tal para o futuro, não me parece que tal promessa e tal futuro se possam ler como "pós", ou se se quiser, esse pós é sempre já um oxímoro, na medida em que esse futuro nunca se dá na forma de um presente,

${ }^{19}$ LUKÁCS, 1968. A miopia do discurso lukaksiano talvez provenha em grande medida do facto de as suas análises nunca terem ultrapassado a barreira psicológica e cultural dos pirinéus.

${ }^{20}$ Entre os vários textos que a isto têm aludido, remeto em especial para um muito interessante texto de Fernando Pinto do Amaral, entitulado "Carlos da Maia e João da Ega: dois vencidos da vida dez anos depois", e incluído no livro Na Órbita de Saturno. 
de uma presença epifânica ou alucinatória. Esse futuro, por um lado, deu-se já nos primeiros escritos de Eça, como me parece que o texto da 4⿳亠丷厂 Conferência do Casino mostra suficientemente. Por outro lado, ele dá-se como passado no episódio do óculo em A Relíquia, na medida em que o discurso realista da "primeira fase" não é de forma alguma abandonado, e é na apresentação fulgurante desse discurso que Eça se descobre como escritor de uma autobiografia tão grande como a sua obra, como escritor de uma autobiografia da escrita. A indecidibilidade passa por aqui também. E não pára, antes resta, como cena maior do que o quadro, como cena que se promete à contemplação futura, no facto de que essa autobiografia medusante se deixa narrar sob a égide de um muito diáfano Cristo crucificado. O óculo narra metonimicamente a história da visão enfraquecida, a história da vida como nau à deriva, a um tempo o apogeu e o fracasso de uma visão monocular da realidade, a ilusão da visão a "olho nú", e não menos a descrença em tal ilusão, materializada no recurso ao óculo como prótese ou suplemento de visão. Eça de Queiroz, fascinado pela cegueira de Teodorico, assina o seu texto como visionário.

\section{Referências Bibliográficas}

AMARAL, Fernando Pinto do. Na Órbita de Saturno. Lisboa: Hiena, 1992.

ARMSTRONG, Nancy. Fiction in the Age of Photography. Mimeo.

BALZAC, Honoré de. La Peau de Chagrin. Paris: Classiques Garnier, 1967.

DE MAN, Paul. Blindness and Insight - The Rhetoric of Contemporary Criticism. Minneapolis: University of Minnesota Press, 1983.

DERRIDA, Jacques. Memoires D'Aveugle-L'autoportrait et autres ruines. Paris: Réunion des Musées Nationaux, 1990.

DERRIDA, Jacques. Parages . Paris: Galilée, 1986. 
FURST, Lilian. All is true- The Claims and Strategies of Realist Fiction. Durham and London: Duke University Press, 1995.

LOPES, Óscar e Saraiva, António José. História da Literatura Portuguesa. XIII ${ }^{\mathrm{a}}$ ed. Porto: Porto Editora, 1985.

LUKÁKS, George. Studies in European Realism . New York: Grosset and Dunlap, 1968.

MATLOCK, Jann. "Censoring the Realist Gaze" in Spetacles of Realism - Gender, Body, Genre. Margaret Cohen and Christopher Pendergast, editors. Minneapolis and London: University of Minnesota Press, 1995.

QUEIROZ, Eça de. A Relíquia. Lisboa: Livros do Brasil, s.d.

RIGNALL, John. Realist Fiction and the Strolling Spectator. London and new York: Routledge, 1992.

SARAIVA, António José. A Tertúlia Ocidental-Estudos sobre Antero de Quental, Oliveira Martins, Eça de Queiroz e outros. IIª ed. revista. Lisboa: Gradiva, 1995.

SARAIVA, António José. As ideias de Eça de Queiroz. Lisboa: Livraria Bertrand, 1982.

\section{Resumo}

Neste artigo pretendo levar a cabo uma releitura de A Relíquia de Eça de Queiroz (bem como de algum do discurso crítico que em Portugal tem surgido sobre a mesma obra) através de uma problematização daquilo a que chamo a retórica da visualidade. A crítica tem sido especialmente desatenta em relação a motivos estético-literários derivados da esfera da visualidade, introduzidos por Eça de Queiroz com uma veemência que me leva crer ser em tudo menos acidental. Tendo referido três desses motivos, o voyerismo, a visão onírica e a visão alegórica, o meu artigo centra-se todavia apenas neste último, por me parecer encerrar um maior grau de complexidade, relativa às ideias da narrativa, à relação dessas ideias com a estrutura do texto, mas também ao nível mais 
amplo do projecto estético-ideológico do escritor no Portugal de oitocentos e até o da cultura portuguesa em geral. Este motivo da visão alegórica cruza-se com o topos clássico do deserdado, mas também, e isto parece-me de particular importancia, com a linguagem da filosofia, que na narrativa de Eça surge como que num quiasmo, ou numa "coincidentia oppositorum": Eça pretende, através da paródia da filosofia, manter-se a salvo da tentação de fazer filosofia. Mas, como sabemos pelo menos desde Aristófanes, a paródia da filosofia é sempre e ainda a mesma filosofia mais a sombra da sua culpa. Ainda aqui, é ainda de uma certa visão ou ausência dela que falamos, ainda que, por uma questão de espaço, não seja possível desenvolver a análise ao ponto que este assuntos certamente merecem. Este artigo insere-se num projecto mais vasto de releitura de um corpus de textos de Eça de Queiroz, do qual fazem parte, para além do texto mencionado, o conto "José Matias" e o livro Lendas de Santos.

\section{Abstract}

In this article I intend to carry out a new reading of Eça de Queiroz's A Relíquia (and of some of the critical discourse that has been produced in Portugal on this novel) through an analysis of what I call the rhetoric of visuality. I have selected three distinct motifs of visuality at play in the novel, although I center my analysis on what I think is the most complex of them: the "allegorical vision." I think this motif both conceals and conveys what the author had in mind as far as aesthetic ideology and political ideals, as well as his vision of nineteenthcentury Portugal and Portuguese culture in general. The motif of allegorical vision should be read in conjunction with the classical topos of the disowned, but also with "between the lines" assumptions about philosophical discourse and representation. This paper is part of a vaster project on a corpus of Eça de Queiroz's texts which includes, in addition to the aforementioned novel, the short story "José Matias" and the book Lendas de Santos. 